\title{
VIABILITY OF THE RAT BLASTOCYST FOLLOWING THE ORAL ADMINISTRATION OF POTASSIUM PERCHLORATE OR POTASSIUM IODIDE TO THE MOTHER
}

\author{
K. BROWN-GRANT AND M. R. SHERWOOD \\ Medical Research Council Neuroendocrinology Unit, Department of Human Anatomy, \\ South Parks Road, Oxford, OXI $3 Q X$
}

(Received 9th March 1971)

During a limited period (Day 3 to Day 5) of early pregnancy the epithelial cells of the endometrium of the rat develop the ability to accumulate inorganic iodide from the blood and to maintain a very high intracellular concentration of this ion (Brown-Grant, 1965; Brown-Grant \& Rogers, 1967). These changes occur just before the normal time of blastocyst implantation but their physiological significance in normal pregnancy is not known. If endometrial accumulation of iodide is prevented by the oral administration of perchlorate to the mother, pregnancy still proceeds normally (Brown-Grant, 1966a). When implantation is delayed by ovariectomy early in pregnancy followed by the administration of progesterone alone or by concurrent lactation, the changes in endometrial iodide concentration still occur but are not immediately followed by implantation (Brown-Grant, 1966b). The possible importance of a high endometrial iodide concentration for the ability of the blastocyst to survive a delay in implantation has been examined. The hypothesis that a high endometrial iodide concentration might, in fact, be detrimental to implantation and thus act as a mechanism for rejecting blastocysts of subnormal viability has also been tested.

In the first experiment, adult Wistar rats late in their fourth or fifth pregnancy were caged singly with males and the date of post-partum mating determined by the finding of spermatozoa in the vaginal smear or a vaginal plug. On this day (Day 0 of pregnancy), the male was removed and the litter size reduced to nine and maintained at this number. The animals were given a $1.0 \%(\mathrm{w} / \mathrm{v})$ solution of $\mathrm{KCl}, \mathrm{KClO}_{4}$ or $\mathrm{KI}$ or a $0.1 \%(\mathrm{w} / \mathrm{v})$ solution of $\mathrm{KI}$ to drink and the daily fluid intake for each rat was determined and the salt intake as mg salt/rat/day calculated. On Day 9 or 10 of the post-partum pregnancy, the litter was removed, weighed and killed and the thyroid glands dissected out, pooled and weighed. On Day 12 or 13, the mother was killed, the number of implantation sites noted and the weight of the sites determined. Thyroid and adrenal weights were also measured. As shown in Table 1, the administration of $1 \% \mathrm{KClO}_{4}$ solution had no significant effect on blastocyst survival or the ability to implant following the removal of the litter. The only 
differences noted were in the relative thyroid weights of both the mothers and the litters.

Oral administration of $1 \% \mathrm{KI}$ did have adverse effects; none of the six rats had implantation sites at autopsy (Table 1), and the mothers were severely affected by this treatment. Three of nine rats died before the experiment was completed, the body weight and fluid intake of the survivors were greatly reduced and the adrenal glands enlarged, and there were many deaths among the litters whose body weights were low. Failure of implantation was probably related to the poor general state of the mothers rather than to a specific effect of iodide. Other rats, given $0.1 \% \mathrm{KI}$ solution to drink had normal fluid intake, maintained healthy litters and had a high rate of implantation (Table 1)

\section{TABLE 1}

AUTOPSY FINDINGS ON RAT LITTERS AND THEIR MOTHERS WHICH HAD BEEN GIVEN PERGHLORATE OR IODIDE SOLUTION DURING NORMAL PREGNANCY OR PREGNANGY WITH LAGTATIONAL DELAY OF IMPLANTATION

\begin{tabular}{|c|c|c|c|c|c|c|}
\hline \multirow{2}{*}{ Treatment } & \multicolumn{4}{|c|}{ Pregnancy with lactation } & \multicolumn{2}{|c|}{ Normal pregnancy } \\
\hline & $1 \% K C l$ & $1 \% \mathrm{KClO}_{4}$ & $1 \% K I$ & $0.1 \% K I$ & $0.1 \% K C l$ & $0.1 \% K I$ \\
\hline Salt intake (mg/rat/day) & $655 \pm 39$ & $615 \pm 11$ & $234 \pm 19$ & $50 \pm 3$ & $34 \pm 1$ & $32 \pm 2$ \\
\hline Final body weight (g) & $246 \pm 9$ & $252 \pm 11$ & $204 \pm 14$ & $233 \pm 6$ & $231 \pm 7$ & $216 \pm 8$ \\
\hline Thyroid (mg/100 g body wt) & $4.5 \pm 0.2$ & $7 \cdot 3 \pm 0 \cdot 3$ & $7 \cdot 2 \pm 0.9$ & $6 \cdot 2 \pm 0 \cdot 2$ & $5 \cdot 6 \pm 0 \cdot 3$ & $6.5 \pm 0.3$ \\
\hline Adrenal (mg/100 g body wt) & $25 \pm 1$ & $23 \pm 1$ & $40 \pm 6$ & $26 \pm 1$ & $28 \pm 1$ & $29 \pm 2$ \\
\hline No. with implantation sites & $9 / 10$ & $7 / 10$ & $0 / 6$ & $9 / 9$ & $9 / 9$ & $8 / 8$ \\
\hline No. of sites/rat with sites & $11 \pm 1$ & $11 \pm 1$ & - & $11 \pm 1$ & $12 \pm 1$ & $11 \pm 1$ \\
\hline Mean weight of sites (mg/rat) & $225 \pm 24$ & $252 \pm 12$ & - & $177 \pm 11$ & $321 \pm 15$ & $276 \pm 23$ \\
\hline Mean weight of young (g) & $16 \pm 1$ & $15 \pm 1$ & $11 \pm 1$ & $14 \pm 1$ & - & - \\
\hline $\begin{array}{l}\text { Mean weight of thyroid } \\
\text { (mg/100 } \mathrm{g} \text { of young) }\end{array}$ & $13 \cdot 6 \pm 0.8$ & $21 \cdot 1 \pm 1 \cdot 0$ & $14 \cdot 0 \pm 1 \cdot 3$ & $14 \cdot 6 \pm 0 \cdot 6$ & 一 & 一 \\
\hline
\end{tabular}

Values are group means \pm S.E. Values in italics are significantly different from the appropriate control values in the $t$ test at $P \leqslant 0.05$.

despite a greatly increased iodide intake. The data of Table 1 show that iodide intake in this group was about $37 \mathrm{mg} / \mathrm{rat} /$ day compared to a calculated normal intake of $60 \mu \mathrm{g} / \mathrm{rat} /$ day based on a daily consumption of $20 \mathrm{~g} /$ day of food pellets containing 3 parts $/ 10^{6}$ of iodine. In a further experiment, rats were mated during the oestrous cycle and given $0 \cdot 1 \%(\mathrm{w} / \mathrm{v}) \mathrm{KCl}$ or $\mathrm{KI}$ solution to drink from Day 0 of pregnancy and were killed on Day 7 . The average iodide intake in this experiment was $24 \mathrm{mg} / \mathrm{rat} /$ day but again no adverse effects on the course of the pregnancy were noted (Table 1).

Earlier observations (Brown-Grant, 1966a) showed that the oral administration of $1 \% \mathrm{KClO}_{4}$ to the mother had no effect on normal pregnancy in the rat and in the present experiments such treatment has been shown to have no adverse effect on the ability of the blastocyst to survive and to implant following a delay in implantation induced by concurrent lactation. Administration of $1 \% \mathrm{KI}$ was harmful to the mother and the sucklings and prevented blastocyst implantation but the specificity of this last effect is doubtful. The high iodide intake induced by the administration of $0.1 \% \mathrm{KI}$ solution had no deleterious 
effect on the course of pregnancy with delayed implantation or normal pregnancy. These experiments have not provided any further information as to the possible functional significance of the endometrial concentration of iodide observed during early pregnancy in the rat.

\section{REFERENCES}

Brown-Grant, K. (1965) The metabolism of iodide by the thyroid gland and by the uterus during early pregnancy in the rat. F. Physiol., Lond. 176, 73.

Brown-GrANT, K. (1966a) Failure of orally administered perchlorate to affect deciduoma formation or pregnancy in the rat. 7 . Reprod. Fert. 12, 353.

Brown-Grant, K. (1966b) Concentration of iodide by the uterus of the rat and the relationship to blastocyst implantation. F. Physiol., Lond. 184, 418.

Brown-Grant, K. \& Rogers, A. W. (1967) The site of concentration of radioiodide in the oviduct and uterus of the overiectomised rat, under the influence of progesterone. F. Anat. 101, 622. 